\title{
Modeling China's offshore production sharing contracts using meta analysis
}

\author{
Hao Hong ${ }^{1}$ and Mark J. Kaiser ${ }^{2 *}$ \\ ${ }^{1}$ School of Business Administration, China University of Petroleum, Beijing 102249, China \\ ${ }^{2}$ Center for Energy Studies, Louisiana State University, Baton Rouge, LA 70803, USA \\ (C) China University of Petroleum (Beijing) and Springer-Verlag Berlin Heidelberg 2010
}

\begin{abstract}
Production sharing contracts have been used in the development of China's offshore petroleum resources since 1982, but the mechanism in which the fiscal terms impact project economics is complicated and not well understood. The purpose of this paper is to model China's offshore production sharing contracts using a probabilistic approach. Cash flows and economic indicators are used for a typical offshore oilfield development, and meta-models are constructed to analyze the basic features of the fiscal system. Applications of the models in contract negotiation are discussed.
\end{abstract}

Key words: Contract negotiation, fiscal models, multiple regression, production sharing contract, simulation

\section{Introduction}

Production sharing contracts (PSCs) are among the most common types of contractual arrangements for petroleum exploration and development (Ge et al, 2004). Under a PSC, the state as the owner of mineral resources engages a international oil company (IOC) as a contractor to provide technical and financial services for exploration and development operations. The resource-owner state is traditionally represented by the government or one of its agencies such as the national oil company (NOC). The IOC acquires an entitlement to a stipulated share of the oil produced as a reward for the risk taken and services rendered. The state, however, remains the owner of the petroleum produced subject only to the contractor's entitlement to its share of production. The government or its NOC usually has the option to participate in different aspects of the exploration and development process. PSCs also frequently provide for the establishment of a joint committee, where both parties are represented, and which monitors the operations (Bindemann, 1999).

The China Offshore Standard PSC (hereinafter referred to as China PSC) has been used in China's offshore petroleum development in cooperation with foreign oil companies since 1982. Similar to other PSCs, the basic fiscal elements in the China PSC include royalty, cost recovery, government participation, profit sharing, and taxation (Wang, 1999). Many aspects of the government/contractor relationship may be negotiated but some are normally determined by legislation

*Corresponding author. email: mkaiser@1su.edu

Received June 25, 2009
(Johnston, 1994). Tax rates are almost always legislated and can be adjusted or revised by the government, impacting the economics of a project. Therefore, it is necessary and important for both the IOC and government to understand the manner in which the fiscal terms impact the economic measures of a project.

Sensitivity analysis and scenario analysis are common methods for uncertainty analysis. Sensitivity analysis is usually used to examine the impact on project economics when only one variable changes (Xu et al, 1999; Blank and Targuin, 2005); scenario analysis is used to compare systems for similar sets of conditions (Black and Roberts, 2006; CERA, 2007). However, these methods can not indicate the functional relationships that exist between economic indicators and the collection of fiscal terms. Kaiser (Kaiser and Pulsipher, 2005; Kaiser, 2007) introduced the metamodeling approach in analyzing petroleum fiscal systems, whereby meta data is generated for variables simulated within a given design space and a meta-model constructed from the meta data. The meta-modeling concept has been used elsewhere, e.g., in software engineering (Liu et al, 2008). The meta-modeling approach in fiscal analysis is useful to understand the structure and sensitivity of fiscal systems to various model parameters.

The purpose of this paper is to analyze the manner in which fiscal terms impact project economics under the China PSC. After introducing the terms of the China PSC and background information on cash flows and economic indicators, the development scenario for an offshore oil field is presented and a meta model for economic indicators is developed. Based on these models, the basic features of the China PSC fiscal system are analyzed and its applications are discussed. 


\section{China offshore PSC fiscal system}

Under China PSCs that involve exploration activities, the IOC must complete a minimum amount of work (minimum work commitment) and bear all the costs during the exploration period. After a commercial discovery is made, these costs can be recovered with production.

In general, the Chinese government or its NOC has the option to take up to $51 \%$ participating interests in the development and production of any discovery and may exercise such option after the IOC has independently undertaken all the exploration risks and costs, completed all the exploration work and viable commercial discoveries have been made. Once the NOC participates in development, the development and operating costs are funded by the NOC and IOC according to their respective percentage of the participating interests. The production allocation under China PSCs is shown in Fig. 1 and summarized as follows.

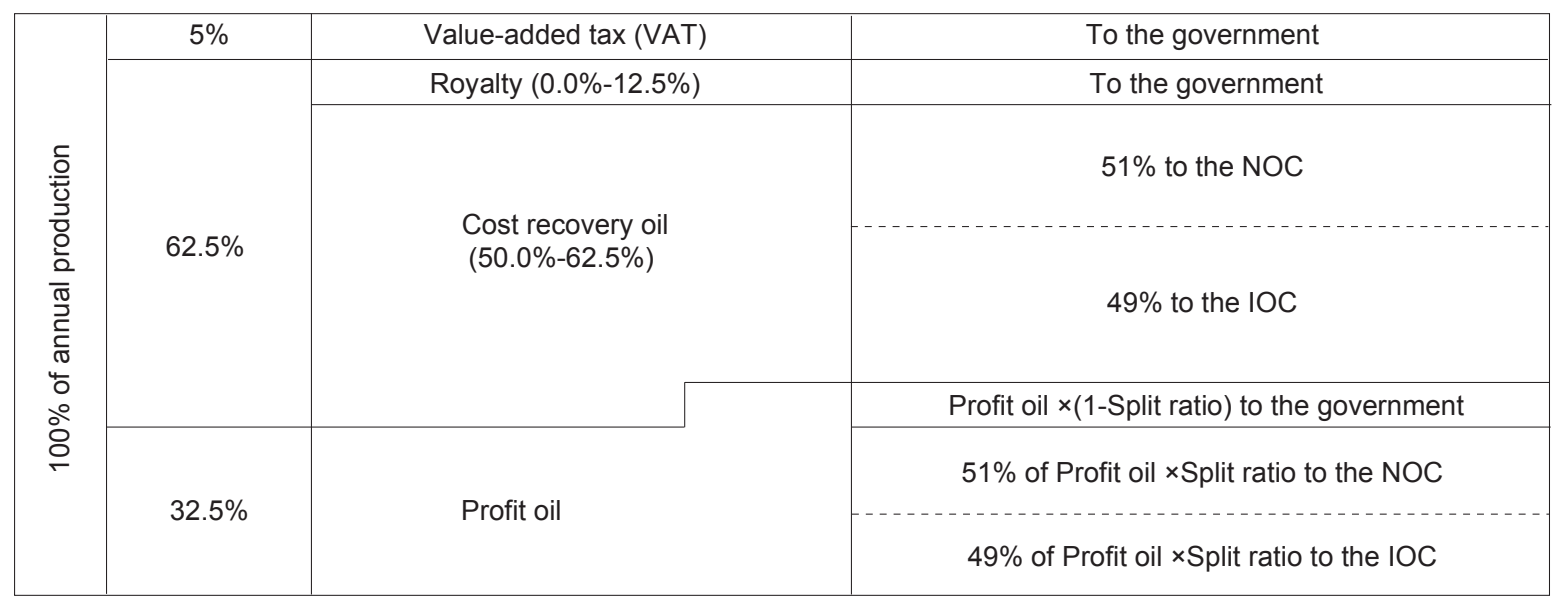

Fig. 1 Production allocation under the China offshore PSC

Value-added tax A value-added tax of 5\% of annual gross production is paid to the government.

Royalty The royalty rate varies on a sliding scale from $0 \%$ to $12.5 \%$ for crude oil and $0 \%$ to $3 \%$ for natural gas (Table 1 ). The first tranche of production that triggers royalty payments is 1 million tons for crude oil and 200 million standard cubic meters for natural gas.

Table 1 Royalty rates for oil and gas

\begin{tabular}{cc}
\hline Annual gross production of oil & Royalty rate \\
\hline Less than 1 million tons & $0 \%$ \\
$1-1.5$ million tons & $4 \%$ \\
$1.5-2.0$ million tons & $6 \%$ \\
$2.0-3.0$ million tons & $8 \%$ \\
3.0-4.0 million tons & $10 \%$ \\
Above 4.0 million tons & $12.5 \%$ \\
\hline Annual gross production of gas & Royalty rate \\
\hline Less than 200 million standard cubic meters & $0 \%$ \\
200-350 million standard cubic meters & $1 \%$ \\
350-500 million standard cubic meters & $2 \%$ \\
Above 500 million standard cubic meters & $3 \%$ \\
\hline
\end{tabular}

Cost recovery limit The cost recovery limit is not given directly under China PSCs, instead, the total amount of the royalty payment and the cost recovery is limited to $62.5 \%$ of annual gross production. If the annual oil production is less than 1 million tons, then there is no royalty payment and the entire $62.5 \%$ of annual production can be used for cost recovery. When the oil production exceeds 1 million tons per year, the percentage of the production used for cost recovery is equal to $62.5 \%$ less the royalty rate. In practice, the cost recovery limit for oil varies from $50 \%$ to $62.5 \%$ of the annual gross production. The sequence, in which costs are recovered, is specified by the contract terms, but typically includes (inorder) operating costs, exploration costs, and development costs and deemed interest. Any excess from cost recovery limit over recovered costs is allocated to the remainder oil (gas). The China PSC allows uplift for development costs with interest, where the interest rate is preset in the contract.

Profit oil $32.5 \%$ of the annual gross production and any excess from cost recovery is distributed to the government and oil companies according to the split ratio " $X$ ". An amount of oil and gas equal to the product of the profit oil multiplied by $(1-X)$ is first distributed to the government as share oil. The balance of the profit oil is then distributed to the NOC and IOC based on each party's participating interest. The split ratio " $X$ " is a sliding scale based on the gross production. An example of the split ratio " $X$ " is shown in Table 2 .

Additional taxes The NOC and IOC also pay the special oil gain levy (SOG levy) and income taxes. In 2006, a special oil gain levy ("SOG levy") was set by the Ministry of Finance of China at rates from $20 \%$ to $40 \%$ on the portion of the monthly weighted average sales price of the crude oil lifted in China exceeding US\$40 per barrel (Table 3). The SOG levy paid can be claimed as a deductible expense for corporate income tax purposes and is calculated based on the actual volume of the crude oil entitled. For tax purposes, the exploration costs are expensed and the development costs 
are depreciated using the straight line method over 6 years. The Corporate Income Tax Law (the "New CIT Law") of the People's Republic of China became effective on 1 January 2008 and unifies the income tax rate for domestic-invested and foreign-invested enterprises at $25 \%$ (previously a rate of $33 \%$ applied).

Table 2 Example of the split ratio under China offshore PSC

\begin{tabular}{cc}
\hline Annual gross production of oil & Split ratio $(X)$ \\
\hline Less than 1 million tons & $100 \%$ \\
2.0-3.0 million tons & $95 \%$ \\
$3.0-5.0$ million tons & $90 \%$ \\
$5.0-7.5$ million tons & $85 \%$ \\
$7.5-10.0$ million tons & $80 \%$ \\
Above 10.0 .0 million tons & $70 \%$ \\
\hline
\end{tabular}

Table 3 Special oil gain levy rates

\begin{tabular}{cc}
\hline Oil price, $\$ /$ bbl & SOG levy rate \\
\hline Less than $\$ 40$ & $0 \%$ \\
$40-45$ & $20 \%$ \\
$45-50$ & $25 \%$ \\
$50-55$ & $30 \%$ \\
$55-60$ & $35 \%$ \\
Above 60 & $40 \%$ \\
\hline
\end{tabular}

\section{Cash flows and economic indicators}

Before an investment decision in an oil and gas project is made, an economic evaluation is performed. The purpose of evaluation is to assess if the revenues generated by the project cover the investment and capital expenditures and the return on capital is consistent with the risk associated with the project and the strategic objectives of the corporation. The results of evaluation are also used in negotiation and decision making. The primary analytic techniques utilize the discounted cash flow approach (Mian, 2002) and several popular measures such as the net present value $(N P V)$ and internal rate of return $(I R R)$ are frequently employed in analysis (Dougherty, 1985; Ross et al, 2006). The $N P V$ is an indicator of how much value an investment or project adds to the investors, while IRR is an indicator of the efficiency or quality of an investment. To understand the attractiveness of a PSC, the take statistic is also analyzed. Division of profits boils down to what is called contractor and government take. Contractor take is the percentage of profits to which the contractor is entitled and provides an important comparison between fiscal systems (Johnston, 2003).

We analyze the fiscal terms from the IOC point of view, and so only the IOC's cash flows and economic indicators are discussed. For the IOC, the cash inflows from a project include the cost recovery and the profit oil allocation; the cash outflows include the exploration costs, development costs, operating costs, SOG levy payment, and income tax payment. The after-tax net cash flow in year $t$ for the IOC takes the form

$$
N C F_{t}=C R_{t}+P O_{t}-O P E X_{t}-C A P E X_{t}-S O G L_{t}-I T_{t}
$$

where, in year $t, N C F_{\text {, }}$ is the after-tax net cash flow to the IOC; $C R_{t}$ is the amount of cost recovery received by the IOC; $P O_{t}$ is the profit oil allocated to the IOC; OPEX is the portion of the total operating costs paid by the IOC according to its participating interests; $C A P E X_{t}$ is the sum of the exploration costs and the portion of the total development costs paid by the IOC according to its participating interests; $S O G L_{t}$ is the special oil gain levy and $I T$, is the income tax paid by the IOC.

Assumed that the project begins in the first year (i.e. $t=1$ ), when the project is sanctioned and run, and is abandoned at $t=k$. Then, the after-tax net cash flow vector associated with oilfield $\mathrm{f}$ for the IOC is denoted as

$$
N C F(f)=\left(N C F_{1}, N C F_{2}, \cdots, N C F_{\mathrm{k}}\right)
$$

The after-tax net cash flow vector serves as the basic element in computation of all the economic indicators associated with the oilfield.

For oilfield $f$ and fiscal system denoted by $F$, the economic indicators $\operatorname{NPV}(f, F), \operatorname{IRR}(f, F)$ and $\operatorname{Take}(f, F)$ of the cash flow vector $N C F(f)$ are computed as

$$
\begin{aligned}
& \operatorname{NPV}(f, F)=\sum_{t=1}^{k} \frac{N C F_{t}}{(1+D)^{t}} \\
& \operatorname{IRR}(f, F)=\{D \mid N P V(f, F)=0\} \\
& \operatorname{Take}(f, F)=\frac{\sum_{t=1}^{k} N C F_{t}}{\sum_{t=1}^{k} N C F T_{t}}
\end{aligned}
$$

where $D$ is the IOC's discount rate and NCFT, is the sum of the net cash flows attributed to the government, NOC and IOC in year $t$.

\section{Meta-modeling}

$N P V, I R R$ and Take are functions of many variables, including the production and cost characteristics of the oilfield, fiscal system, future oil and gas price, and various modeling assumptions. The relations are complex and complicated, but it is possible to understand the interactions of the variables and their related influences by developing metamodels. A cash flow model of the system is first constructed and parameters of the system are defined through specified design intervals. The parameters of the system are sampled from the design space and evaluated with the cash flow model. The results of the model and the system parameters are then analyzed and meta-models are developed from the 
generated data. The approach is as follows:

1) Specify the variable set $\psi$ and determine the design interval $l_{i} \leq \psi_{i} \leq u_{i}, i=1, \cdots, \mathrm{n}$, for each parameter of interest, where the values of $l_{i}$ and $u_{i}$ are user-defined and account for a reasonable range of the historic uncertainty (or expected variation) associated with each parameter. Denote the design space as $\Omega$ :

$$
\Omega=\left\{\psi=\left(\psi_{1}, \cdots, \psi_{n}\right) \mid l_{i} \leq \psi_{i} \leq u_{i}, \quad i=1, \cdots, n\right\}
$$

2) Sample the components parameters $\psi^{*}=\left(\psi_{1}{ }^{*}, \cdots, \psi_{n}{ }^{*}\right)$ uniformly over the design space and compute the economic measures $\varphi\left(f, F\left(\psi^{*}\right)\right)$.

3) Based on the data sets $\left\{\psi^{*}\right\}$ and $\left\{\varphi\left(f, F\left(\psi^{*}\right)\right)\right\}$, estimate for each measure $\varphi$ the functional relation

$$
\varphi(f, F(\psi))=\alpha_{0}+\sum_{i=1}^{n} \alpha_{i}(\varphi) \psi_{i}
$$

where the coefficients $\alpha_{i}(\varphi)$ are determined through regression modeling.

\section{Model development}

\section{Development scenario}

The development scenario for an offshore oilfield located in Bohai Bay (China) is made based on an estimated gross ultimate recovery of 13.35 million barrels of oil equivalent (MMBOE). The exploration costs are $\$ 51$ million. Total development costs are estimated at $\$ 51.787$ million. The estimated variable operating cost is $\$ 1.8 / \mathrm{bbl}$ with an annual fixed operating cost of $\$ 4$ million and additional workover expenditures of $\$ 6$ million in year 13. The projected production, capital expenditures, and operating expenditures are shown in Table 4.

\section{Model Parameters}

The IOC's discount rate is assumed to be $10 \%$. The fiscal term variables include the value-added tax rate (VAT), cost recovery limit $(C R L)$, deemed interest rate $(D I R)$, split ratio $(S R)$, government participating interest $(G P I)$, income tax rate $(T A X)$, and SOG levy $(S O G)$. Royalty is not taken into consideration since the annual production from this oilfield is much lower than the first tranche of 1 million tons. The split ratio is a sliding scale based on the annual production. We consider only the first tranche of the split ratio because of the low production rates. The SOG levy rate is a sliding scale based on oil prices. The first tranche of SOG levy rate is assumed to be a variable of the system. The sequential tranches of rates will change when the first tranche rate changes, but the intervals are kept constant at $5 \%$. Oil price $(P)$ is also a key parameter in the model.

\section{Design Space}

The design space is defined from the collection of variables as:

$$
\begin{aligned}
& \Omega=\{(P, V A T, C R L, D I R, S R, G P I, T A X, S O G) \mid 30 \leq P \leq 80, \\
& 2 \% \leq V A T \leq 10 \%, 40 \% \leq C R L \leq 80 \%, 2 \% \leq D I R \leq 10 \%, \\
& 95 \% \leq S R \leq 100 \%, 20 \% \leq G P I \leq 60 \%, 15 \% \leq T A X \leq 35 \%, \\
& 10 \% \leq S O G \leq 40 \%\}
\end{aligned}
$$

\begin{tabular}{|c|c|c|c|c|}
\hline Year & $\begin{array}{l}\text { Production } \\
\text { MBOE }\end{array}$ & $\begin{array}{l}\text { Operating } \\
\text { costs, \$M }\end{array}$ & $\begin{array}{c}\text { Exploration } \\
\text { costs, \$M }\end{array}$ & $\begin{array}{c}\text { Development } \\
\text { costs, \$M }\end{array}$ \\
\hline 1 & & & 12218 & \\
\hline 2 & & & 23258 & \\
\hline 3 & & & 7115 & 4973 \\
\hline 4 & 1216 & 4189 & 8409 & 46814 \\
\hline 5 & 2256 & 8062 & & \\
\hline 6 & 1658 & 6985 & & \\
\hline 7 & 1168 & 6103 & & \\
\hline 8 & 956 & 5721 & & \\
\hline 9 & 833 & 5499 & & \\
\hline 10 & 740 & 5332 & & \\
\hline 11 & 671 & 5207 & & \\
\hline 12 & 618 & 5112 & & \\
\hline 13 & 576 & 11036 & & \\
\hline 14 & 541 & 4973 & & \\
\hline 15 & 512 & 4921 & & \\
\hline 16 & 484 & 4871 & & \\
\hline 17 & 460 & 4828 & & \\
\hline 18 & 424 & 4763 & & \\
\hline 19 & 238 & 4428 & & \\
\hline Total & 13350 & 92029 & 51000 & 51787 \\
\hline
\end{tabular}

based on the historic and expected future oil price and fiscal terms.

Table 4 Projected production, capital expenditures and operating costs

Notes: MBOE-Thousand barrels of oil equvalent; \$M-Thousand dollars

\section{Results of regression models}

Regression models are constructed for the IOC's economic indicators $N P V(f, F), \operatorname{IRR}(f, F)$ and $\operatorname{Take}(f, F)$ through 1000 values sampled uniformly over the design space $\Omega$. The results of the regression models are shown in Table 5 .

Table 5 shows that the value-added tax, government participating interest, income tax and SOG levy have negative correlation with all the three economic indicators, while the cost recovery limit, deemed interest rate, and split ratio have positive impact. The positive correlation between the deemed interest rate and $N P V$ or $I R R$ is not statistically significant. In addition, the IOC's $N P V$ and $I R R$ have positive correlation with oil price, but Take has a negative correlation.

The regression models are written as follows and can be used to evaluate any combination of parameters within the design space. 
Table 5 Regression results

\begin{tabular}{cccc}
\hline Model & \multicolumn{1}{c}{$Y=\alpha_{0}+\alpha_{1} P+\alpha_{2} V A T+\alpha_{3} C R L+\alpha_{4} D I R+\alpha_{5} S R+\alpha_{6} G P I+\alpha_{7} T A X+\alpha_{8} S O G$} \\
Coefficient & $N P V, \$ M M$ & IRR, \% & Take, \% \\
\hline$\alpha_{0}$ & $-14.46(-0.95)$ & $9.15(2.30)$ & $53.32(17.75)$ \\
$\alpha_{1}$ & $1.64(105.88)$ & $0.51(126.28)$ & $-0.21(-68.74)$ \\
$\alpha_{2}$ & $-144.33(-15.03)$ & $-39.78(-15.91)$ & $-58.75(-31.15)$ \\
$\alpha_{3}$ & $3.53(1.85)$ & $2.51(5.05)$ & $0.44(1.18)$ \\
$\alpha_{4}$ & $9.47(0.98)$ & $3.92(1.56)$ & $4.73(2.50)$ \\
$\alpha_{5}$ & $89.08(5.78)$ & $20.03(4.99)$ & $36.88(12.18)$ \\
$\alpha_{6}$ & $-129.94(-67.44)$ & $-28.26(-56.35)$ & $-60.47(-159.81)$ \\
$\alpha_{7}$ & $-108.77(-28.80)$ & $-29.22(-29.72)$ & $-47.94(-64.63)$ \\
$\alpha_{8}$ & $-40.44(-15.72)$ & $-11.32(-16.91)$ & $-12.92(-25.58)$ \\
\hline $\mathrm{R}^{2}$ & 0.95 & 0.96 & 0.97 \\
\hline
\end{tabular}

Note: $t$-statistics are provided in parenthesis

$$
\begin{aligned}
N P V= & -14.46+1.64 P-144.33 V A T+3.53 C R L+9.47 D I R \\
& +89.08 S R-129.94 G P I-108.77 T A X-40.44 S O G \\
I R R= & 9.15+0.51 P-39.78 V A T+2.51 C R L+3.92 D I R+20.03 S R \\
- & 28.26 G P I-29.22 T A X-11.32 S O G \\
\text { Take }= & 53.32-0.21 P-58.75 V A T+0.44 C R L+4.73 D I R+36.88 S R \\
& -60.47 G P I-47.94 T A X-12.92 S O G
\end{aligned}
$$

\section{Analysis of fiscal system}

The meta-models indicate some general features of the China PSC fiscal system. The royalty mechanism did not play a significant role because of the high production requirement for the first tranche, and would not be a relevant parameter in negotiation. The government participating interest and split ratio are significant factors, but the cost recovery limit and deemed interest rate have relatively minor impact. This indicates that the government participating interest and split ratio are more significant parameters than the selection of the cost recovery limit and deemed interest rate. It seems that the high cost recovery limit and uplift of development costs with interest have not provided significant incentives to foreign investors as expected. Thus, if necessary, the IOC may make some concession in negotiation on the cost recovery limit and deemed interest rate, while they should try to have the government participating interest as low as possible and the split ratio as high as possible.

On the other hand, the value-added tax rate, income tax rate, and SOG levy rate are usually not negotiable. Nevertheless, oil companies should recognize the impact caused by the potential changes in these variables. Changing the value-added tax rate has the largest impact on the IOC's economic indicators. This result is not unexpected, because only the value-added tax is levied based on gross production or gross revenue. In addition, high oil price would lead to low IOC's Take, which is probably caused by the SOG levy. Fig. 2 shows that with no SOG levy, the IOC's Take increase with oil price and reaches a relatively stable level. However, if the SOG levy is considered, the IOC's Take would decline after the oil price exceeds $\$ 40 / \mathrm{bbl}$. IOCs thus need to carefully consider the potential impact of the SOG level on the economic viability of the project.

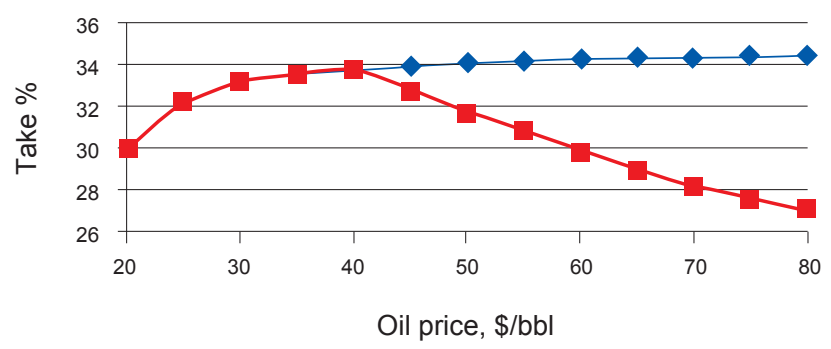

-Take without SOG _ - Take with SOG

Fig. 2 IOC's Take with and without SOG levy

\section{Application}

The sensitivity of the economic indicators to various fiscal terms is readily understood. The IOC's $N P V$ will increase \$0.0353 million, \$0.0947 million, and \$0.891 million if the cost recovery limit, deemed interest rate and split ratio rises $1 \%$, respectively; and it will decrease $\$ 1.443$ million, \$1.299 million, \$1.088 million and \$0.404 million when the valueadded tax rate, government participating interest, income tax rate and SOG rate increases $1 \%$, respectively. In the same way, we can learn about how much the IRR or Take will change when one or more variables change.

Using the meta-models, the IOC can directly evaluate and compare various fiscal term combinations in the process of negotiation and select an appropriate strategy by tradeoffs between risk and reward. For example, for $(P, V A T, D I R$, $T A X, S O G)=(50,5 \%, 9 \%, 25 \%, 20 \%)$,

$$
\begin{aligned}
& N P V=25.96+3.53 C R L+89.085 S R-129.94 G P I \\
& I R R=23.42+2.51 C R L+20.03 S R-28.26 G P I \\
& \text { Take }=25.78+0.44 C R L+36.88 S R-60.47 G P I
\end{aligned}
$$

suppose that the cost recovery limit, split ratio and government participating interest are negotiable. If $C R L=62.5 \%, S R=100 \%$ and $G P I=51 \%$, then $N P V=\$ 50.97$ million, $I R R=30.61 \%$ and Take $=32.10 \%$; if $C R L=50 \%$, $S R=98 \%$ and $G P I=45 \%$, then $N P V=\$ 56.55$ million, $I R R=31.59 \%$ and Take $=34.93 \%$. So the combination of $(C R L$, $S R, G P I)=(50 \%, 98 \%, 45 \%)$ is better for the IOC than the combination of $(C R L, S R, G P I)=(62.5 \%, 100 \%, 51 \%)$. Many other applications are possible.

\section{Conclusion}

To determine the manner in which fiscal terms impact project economics under the China PSC, an analytic 
approach is used to develop generalized functional relations (meta-models) of the NPV, IRR and Take in terms of fiscal parameters. The models illustrate that the government participating interest and split ratio are more significant parameters than the cost recovery limit and deemed interest rate. In addition, the sizes of most fields are smaller than 1 million tons of the production threshold for royalty payment, so the royalty is not a key parameter in China PSC negotiation. The IOC should pay close attention to change in the value-added tax rate because of its significant impact on economic indicators. We also showed that high oil prices will lead to low IOC Take and the SOG levy may reduce the attractiveness of the China PSC.

The meta-models describe the linear relationship between the economic indicators and fiscal variables and can be conveniently used in PSC negotiation. The meta-models show clearly the sensitivity of the economic indicators to the changes of fiscal terms and provide a valuation for parameter changes. With the meta-models, both IOC and NOC can evaluate and compare combination strategies.

\section{References}

Bindemann K. Production-Sharing Agreements: An Economic Analysis. Oxford Institute for Energy Studies. 1999

Black A J and Roberts M. C. Comparing petroleum fiscal regimes under oil price uncertainty. Resources Policy. 2006. 31(2): 95-105

Blank L T and Targuin A J. Engineering Economy (6th edition). McGraw-Hill Higher Education. 2005

Cambridge Energy Research Associates. A comparison of fiscal regimes.
2007 from http://lba.legis.state.ak.us/aces/doc_log/2007-11-0_cera a_comparison_of fiscal_regimes presented to_sen_fin.pdf

Dougherty E L. Guidelines for proper application of four commonly used investment criteria. In SPE paper 13770, SPE Hydrocarbon Economics and Evaluation Symposium. Dallas. 1985. 101-15

Ge A J, Guo P and Xu H. Theory and Practice of Oil and Gas Cooperation. Beijing: Petroleum Industry Press. 2004 (in Chinese)

Johnston D. International Petroleum Fiscal Systems and Production Sharing Contracts. Tulsa: PennWell Books. 1994

Johnston D. International Exploration Economics, Risk, and Contract Analysis. Tulsa: PennWell Books. 2003

Kaiser M J and Pulsipher A G. A meta-modeling approach to fiscal system analysis-IV. Fiscal design: A case study of Girassol. Petroleum Accounting and Financial Management Journal. 2005 (July):1-10

Kaiser M J. Fiscal system analysis_concessionary systems. Energy. 2007. 32(11): 2135-2147

Liu H, Ma Z Y and Shao W Z. Progress of research on meta-modeling. Software Journal. 2008. 19(6): 1317-1327 (in Chinese)

Mian M A. Project Economics and Decision Analysis. Vol. 1. Deterministic Models. Tulsa: PennWell Books. 2002

Ross S A, Westerfield R W and Jaffe J. Corporate Finance (8th edition). McGraw-Hill/Irwin. 2008

Wang Y. Practice and Lessons from China National Offshore Oil Corporation in Cooperation with Foreign Enterprises. Beijing: Yan Shi Press. 1999 (in Chinese)

Xu Q, Yang X Y and Wang Y L. Evaluation Methods of Oilfields Development and Construction Projects for Cooperation with Foreign Oil Companies. Beijing: Petroleum Industry Press. 1999 (in Chinese)

(Edited by Zhu Xiuqin) 